\title{
Analysis on the Effects of the Human Body on the Performance of Wearable Textile Antenna in Substrate Integrated Waveguide Technology
}

\author{
Mariam El gharbi \\ Abdelmalek Essaâdi University, \\ Faculty of Sciences, \\ Tetuan-Morocco. \\ elgharbimariam93@gmail.com
}

\author{
Saida Ahyoud \\ Abdelmalek Essaâdi University, \\ Faculty of Sciences, \\ Tetuan-Morocco. \\ sahyoud@uae.ac.ma
}

\author{
Noura Aknin \\ Abdelmalek Essaâdi University, \\ Faculty of Sciences, \\ Tetuan-Morocco. \\ noura.aknin@uae.ac.ma
}

\author{
Ignacio Gil \\ Universitat Politècnica de Catalunya, \\ Department of Electronic Engineering, \\ Terrassa-Spain. \\ ignasi.gil@upc.edu
}

\author{
Raúl Fernández-Garcia \\ Universitat Politècnica de Catalunya, \\ Department of Electronic Engineering, \\ Terrassa-Spain. \\ raul.fernandez-garcia@upc.edu
}

\begin{abstract}
A wearable textile circular ring slot antenna based on a substrate integrated waveguide cavity is presented. In this paper, the focus is on studying and understanding the technical behavior of the SIW textile antenna when located near the human body. Thus, based on the electrical properties of conductive material and the dielectric characteristics of the Felt substrate, a $5.5 \mathrm{GHz}$ electro-textile antenna was designed. The proposed antennas are simulated in free space, while the performance of antenna is investigated for on-body condition. The simulated impedance bandwidths of the proposed antenna in free space and on phantom are $120 \mathrm{MHz}$ and $110 \mathrm{MHz}$ at $5.5 \mathrm{GHz}$ respectively. The efficiencies of the antenna at $5.5 \mathrm{GHz}$ are $95.8 \%$ in free space, and $91.6 \%$ on phantom, respectively, meanwhile the gains of that are $8.64 \mathrm{~dB}$ and $9.35 \mathrm{~dB}$, respectively.
\end{abstract}

Keywords-SIW (Substrate Integrated Waveguide); Cavitybacked antenna; wearable antenna; Human body model.

\section{I. ${ }^{n} \quad$ INTRODUCTION}

Wearable antennas are highly in demand to support several wearable technologies due to the advantage of being flexible, lightweight and easily integrated with clothing[1]. Creating structures that conform to body shape contribute to the development of smart textile systems for wearable applications. In the field of wearable and flexible electronics, the substrate integrated waveguide (SIW) technology is suitable for application into wearable textile systems and clothing, as this topology ameliorate the isolation of the electromagnetic fields from its environment[2]. Therefore, SIW based cavity-backed designs are promising due to their low-profile construction, low insertion loss, simple fabrication and planar structure[3].
These advantages have been the focus of various studies on cavity-backed SIW textile antennas in recent years. A SIW textile antenna for dual-band MIMO applications was presented in [4]. In[5], a wearable textile antenna in SIW technology was reported. Furthermore, a solar harvester based on integrated dual-band textile antenna using SIW technology was demonstrated in [6], and a leather substrate SIW textile tri-band antenna was proposed in [7].

In this paper, detailed analysis was carried out by studying the SIW textile antenna characteristics based on phantom of human body parts through the reflection coefficient, radiation pattern, gain and efficiency. Antenna design and performance evaluation have been realized using CST Microwave Studio. The proposed antenna has the advantages of higher gain than [4]-[8], due to the circular ring slot and the SIW cavity feed structure.

\section{II. " ANTENNA DESIGN AND THE PHANTOM MODEL}

\section{A. SIW Cavity-Backed Design}

A substrate integrated waveguide structure is designed in a single layered dielectric substrate by implanting metallic via-array which realize the lateral walls of the SIW[9]. In order to reduce leakage of electromagnetic energy from the gap between two adjacent vias, it is important to satisfy $\mathrm{P} \leq$ $2 D$, where $\mathrm{D}$ is the diameter of the vias, $\mathrm{P}$ is the separation between consecutive vias [10]. The structure of the SIW cavity can be equivalently analyzed by the classical rectangular waveguide cavity. In order to calculate the dimensions of the SIW cavity required to excite the TE101 dominant mode, the dimensions of the cavity should be determined based on the following relations[11]: 


$$
\mathrm{f}_{\mathrm{r}}\left(\mathrm{TE}_{101}\right)=\frac{\mathrm{c}}{2 \sqrt{\varepsilon_{\mathrm{r}}}} \sqrt{\left(\frac{1}{\mathrm{~W}_{\text {eff }}}\right)^{2}+\left(\frac{1}{\mathrm{~L}_{\mathrm{eff}}}\right)^{2}}
$$

Where $\varepsilon_{r}, \mathrm{~W}_{\text {eff }}$ and $\mathrm{L}_{\text {eff }}$ are the relative permittivity and the effective width and length of the SIW cavity, respectively. The effective width and length of the SIW cavity can be approximated as follows[12]:

$$
\begin{gathered}
\mathrm{W}_{\text {eff }}=\mathrm{W}_{\text {SIW }}-\frac{\mathrm{D}^{2}}{0.95 \mathrm{P}} \\
\mathrm{L}_{\mathrm{eff}}=\mathrm{L}_{\mathrm{SIW}}-\frac{\mathrm{D}^{2}}{0.95 \mathrm{P}}
\end{gathered}
$$

\section{B. Antenna Topology}

The geometry and design parameters of the SIW textile antenna is shown in Fig.1. There are two elements in the design of SIW textile antenna; conductive textile as the radiating element and non-conductive textile as the nonradiating (substrate) element. For the radiating element, consists of a top patch with a circular ring slot with a radius $\mathrm{R}$ and a bottom ground plane, these two conductors are connected by shorting vias. The felt textile material is chosen as the substrate due to its low dielectric constant $\left(\varepsilon_{\mathrm{r}}=1.2\right)$, loss tangent of 0.0013 and thickness of $0.7 \mathrm{~mm}$. The dimensions of the SIW cavity are determined to maintain the dominant resonant frequency around $5.5 \mathrm{GHz}$ from equations (1) - (3) which are optimized under CST.

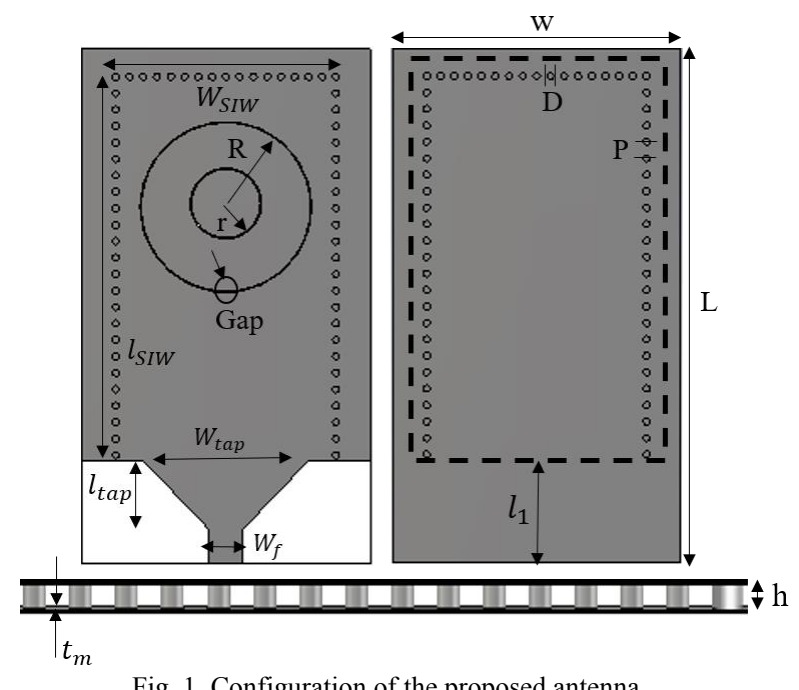

Fig. 1. Configuration of the proposed antenna.

TABLE I DIMENSIONS (MM) OF THE PROPOSED ANTENNA.

\begin{tabular}{|l|l|l|l|l|l|c|c|}
\hline Parameter & $\mathrm{W}$ & $\mathrm{P}$ & $\mathrm{R}$ & $W_{\text {SIW }}$ & $W_{\text {tap }}$ & $t_{m}$ & $\mathrm{~h}$ \\
\hline Value & 42 & 2 & 12.5 & 30 & 22.1 & 0.035 & 0.7 \\
\hline Parameter & $\mathrm{L}$ & $\mathrm{D}$ & $\mathrm{r}$ & $l_{\text {SIW }}$ & $l_{\text {tap }}$ & $W_{f}$ & $l_{1}$ \\
\hline Value & 73 & 1 & 5 & 58 & 12 & 3.114 & 15 \\
\hline
\end{tabular}

\section{SIW Textile Antenna With The Phantom Model}

The proposed antenna has been investigated for on-body conditions at $5.5 \mathrm{GHz}$. SIW textile antenna should operate on the human body and be specifically placed at anybody locations such as the wrist, arm, leg or shoulder. For that reason, the effects must be investigated and analyzed. In order to understand the impact of on-body condition to a wearable SIW antenna, two situations (free space and with phantom) were simulated and studied in this article. The proposed antenna is placed on a three-layer tissue model to analyze the performance of antenna in biological environment while simulation. The model consists of skin, fat and muscle as shown in Fig.2. The dielectric properties of each tissue layer are listed in Table 2, the values of dielectric for tissue model are taken according to [3].

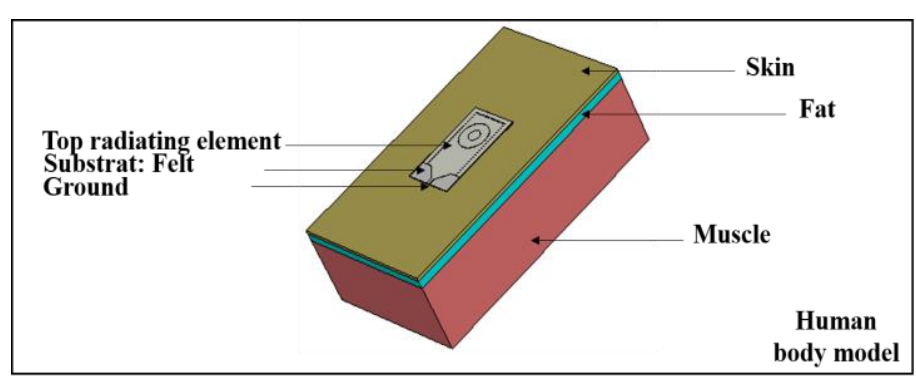

Fig.2. Proposed antenna with human tissue.

TABLE II PROPERTIES OF HUMAN TISSUES AT 5.5GHZ.

\begin{tabular}{|c|c|c|c|}
\hline Tissues & Skin & Fat & Muscle \\
\hline$\varepsilon^{\prime}$ & 35.68 & 5.004 & 49.66 \\
\hline$\varepsilon^{\prime \prime}$ & 11.82 & 1.032 & 16.99 \\
\hline Thickness $(\mathrm{mm})$ & 3 & 7 & 60 \\
\hline
\end{tabular}

\section{III. ${ }^{n}$ RESULTS AND DISCUSSION}

The reflection coefficients performance of the antenna in free space and on the phantom are illustrated in Fig.3. The resonant frequency shifted slightly to the left when the antenna was simulated in the presence of the human phantom. The simulated $10-\mathrm{dB}$ reflection coefficient bandwidth of the antenna in free space was $120 \mathrm{MHz}$ ranging from $5.44 \mathrm{GHz}$ to $5.56 \mathrm{GHz}$ and on the phantom was $110 \mathrm{MHz}$ ranging from $5.40 \mathrm{GHz}$ to $5.51 \mathrm{GHz}$.



Fig.3. Simulated reflection coefficients of the antenna in free space and on human body equivalent phantom. 
Fig.4 shows the radiation pattern of the SIW textile antenna for both cases in E-plane and H-plane, respectively. Based on the diagrams, slight deformation in radiation pattern was remarked which indicates that in terms of radiation behavior, the on-body condition did not give highly influence as compared to the free space environment. The performance of the proposed antenna appears to be in good conformity when in free space and with human phantom.

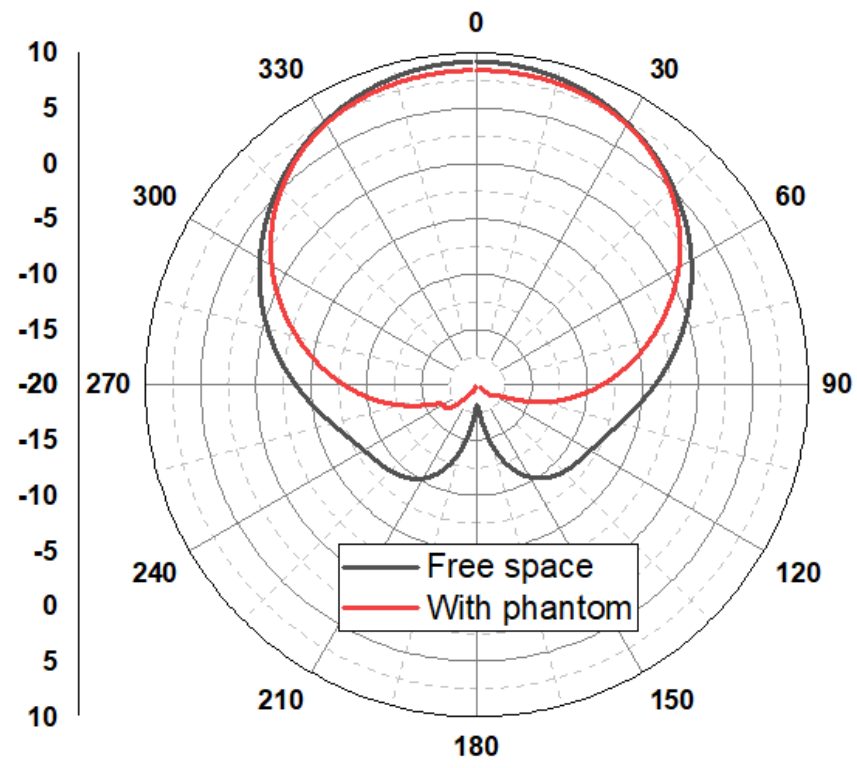

(a)

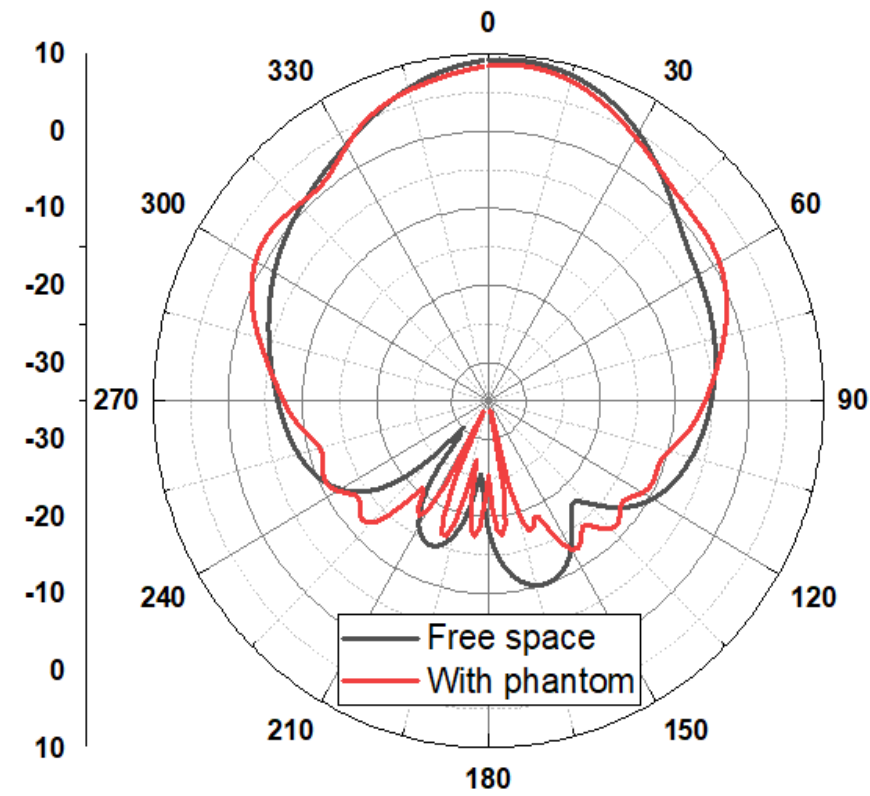

(b)

Fig.4. Simulated radiation pattern at 5.5GHz: (a) Electric field plane (EPlane); (b) Magnetic field plane (H-Plane).
To analyze the directivity of the SIW textile antenna in free space and while mounted on the human tissue, Fig.5 represents the $3 \mathrm{D}$ directivity of the proposed antenna. The main direction of propagation is outward from the antenna which is good for using with the human body.
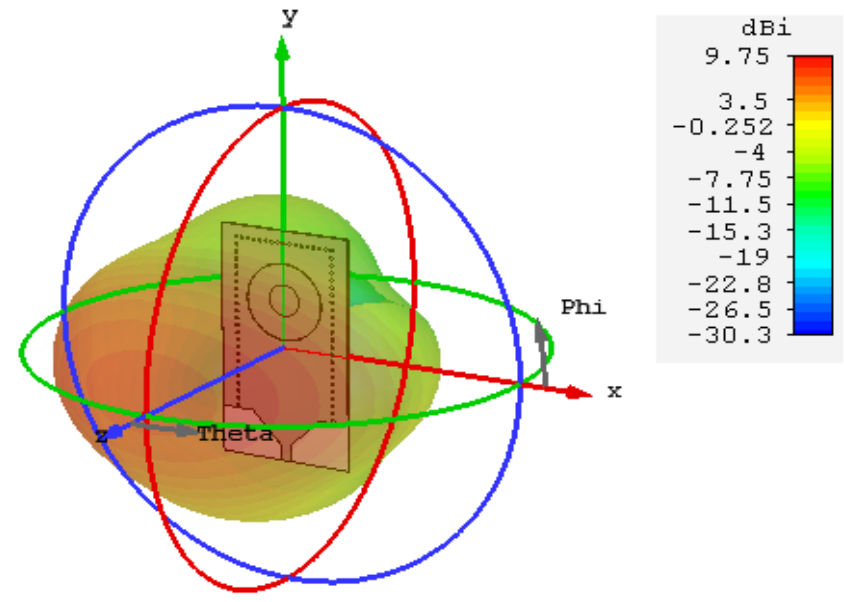

(a)



9. 43

3.18

$-0.568$

$-4.32$

$-8.07$

$-15.6$

$-19.3$

$-23.1$

$-26.8$

-26.8
-30.6

Fig. 5. 3D radiation pattern for the proposed antenna at 5.5GHz: (a) Free space, (b) with phantom.

Fig. 6 presents the gain and efficiency of the proposed SIW textile antenna. It achieves up to an $95 \%$ efficiency in free space and up to a $90 \%$ efficiency when mounted on the phantom at $5.5 \mathrm{GHz}$, it also obtains more than an $8 \mathrm{~dB}$ gain in both cases.

A comparison between the specifications of the proposed SIW cavity-backed textile antenna and those of previous works can be seen in Table 3. As shown in the table, the proposed SIW textile antenna exhibits improvements in gain and efficiency. 




(a)



(b)

Fig. 6. (a) Efficiency, (b) Gain of the proposed antenna.

TABLE III COMPARISON OF RELATED WORKS IN THE LITERATURE.

\begin{tabular}{|c|c|c|c|c|c|}
\hline \multicolumn{2}{|c|}{ Properties } & $\begin{array}{c}\text { Matching } \\
\text { band (MHz) }\end{array}$ & $\begin{array}{c}\text { BW } \\
(\mathrm{MHz})\end{array}$ & $\begin{array}{c}\text { Gain } \\
(\mathrm{dB})\end{array}$ & $\begin{array}{c}\text { Eff } \\
(\%)\end{array}$ \\
\hline \multirow{2}{*}[13]{} & Free space & $5725-5875$ & 170 & 5.8 & 85.6 \\
\cline { 2 - 6 } & $\begin{array}{c}\text { With } \\
\text { phantom }\end{array}$ & $5725-5875$ & 170 & 5.7 & 69 \\
\hline$[14]$ & \begin{tabular}{c} 
Free space \\
\multirow{2}{*}{ Frenyyyyy}
\end{tabular} & $5150-5850$ & 700 & 6 & - \\
\hline
\end{tabular}

\begin{tabular}{|c|c|c|c|c|c|}
\hline \multirow{2}{*}[4]{} & $\begin{array}{c}\text { With } \\
\text { phantom }\end{array}$ & $5110-5980$ & 870 & 6.08 & -- \\
\cline { 3 - 6 } & Free space & $2367-2530$ & 163 & 3.2 & 55 \\
\cline { 2 - 6 } & $\begin{array}{c}\text { With } \\
\text { phantom }\end{array}$ & $2374-2535$ & 161 & 2 & 50 \\
\cline { 2 - 6 } This & $\begin{array}{c}\text { Free space } \\
\text { Work }\end{array}$ & $5440-5560$ & 120 & 9.35 & 95 \\
\cline { 2 - 6 } & $\begin{array}{c}\text { With } \\
\text { phantom }\end{array}$ & $5400-5510$ & 110 & 8.64 & 91 \\
\hline
\end{tabular}

\section{IV. ${ }^{\mathrm{C}}$ CONCLUSION}

In this paper, a wearable textile circular ring slot antenna based on a substrate integrated waveguide cavity is presented. The proposed antenna performance is studied both in free space and on the human tissue model. The SIW textile antenna exhibited higher gain and efficiency in both cases. In addition, this structure is light weight, flexible and low cost, thus making this antenna wellsuited for on-body use.

\section{REFERENCES}

[1] N. H. M. Rais, P. J. Soh, F. Malek, S. Ahmad, N. B. M. Hashim, and P. S. Hall, "A review of wearable antenna," in 2009 Loughborough antennas \& propagation conference, 2009, pp. 225-228.

[2] C. Lopes, C. Loss, R. Salvado, P. Pinho, S. Agneessens, and H. Rogier, "Development of substrate integrated waveguides with textile materials by manufacturing techniques," in 2nd International Electronic Conference on Sensors and Applications, 2015, pp. 1-6.

[3] D. Chaturvedi, A. Kumar, and S. Raghavan, "Wideband HMSIWbased slotted antenna for wireless fidelity application," IET Microwaves, Antennas \& Propagation, vol. 13, no. 2, pp. 258-262, 2019.

[4] S. Yan, P. J. Soh, and G. A. E. Vandenbosch, "Dual-band textile MIMO antenna based on substrate-integrated waveguide (SIW) technology," IEEE Transactions on Antennas and Propagation, vol. 63, no. 11, pp. 4640-4647, 2015.

[5] R. Moro, S. Agneessens, H. Rogier, and M. Bozzi, "Wearable textile antenna in substrate integrated waveguide technology," Electronics letters, vol. 48, no. 16, pp. 985-987, 2012.

[6] S. Lemey, F. Declercq, and H. Rogier, "Dual-band substrate integrated waveguide textile antenna with integrated solar harvester," IEEE Antennas and wireless propagation letters, vol. 13, pp. 269272, 2014.

[7] B. Mandal and S. K. Parui, "Wearable tri-band SIW based antenna on leather substrate," Electronics Letters, vol. 51, no. 20, pp. 1563-1564, 2015.

[8] Y. Hong, J. Tak, and J. Choi, "An all-textile SIW cavity-backed circular ring-slot antenna for WBAN applications," IEEE Antennas and Wireless Propagation Letters, vol. 15, pp. 1995-1999, 2016. 
[9] A. Kumar and S. Raghavan, "Bandwidth Enhancement of Substrate Integrated Waveguide Cavity-backed Bow-tie-complementary-ringslot Antenna using a Shorted-via," Defence Science Journal, vol. 68, no. 2, p. 197, 2018.

[10] M. Bozzi, A. Georgiadis, and K. Wu, "Review of substrate-integrated waveguide circuits and antennas," IET Microwaves, Antennas \& Propagation, vol. 5, no. 8, pp. 909-920, 2011.

[11] A. Kumar and S. Raghavan, "Broadband SIW cavity-backed triangular-ring-slotted antenna for Ku-band applications," AEUInternational Journal of Electronics and Communications, vol. 87, pp. 60-64, 2018.

[12] A. Kumar, D. Chaturvedi, and S. Raghavan, "SIW cavity-backed circularly polarized square ring slot antenna with wide axial-ratio bandwidth," AEU-International Journal of Electronics and Communications, vol. 94, pp. 122-127, 2018.

[13] S. Agneessens and H. Rogier, "Compact half diamond dual-band textile HMSIW on-body antenna," IEEE Transactions on Antennas and Propagation, vol. 62, no. 5, pp. 2374-2381, 2014.

[14] H. Lee and J. Choi, "A compact all-textile on-body SIW antenna for IoT applications," in 2017 IEEE International Symposium on Antennas and Propagation \& USNC/URSI National Radio Science Meeting, 2017, pp. 825-826. 